\title{
Research Article \\ Strong Convergence Theorems for a Countable Family of Lipschitzian Mappings
}

\author{
Weerayuth Nilsrakoo' ${ }^{1}$ and Satit Saejung ${ }^{2}$ \\ ${ }^{1}$ Department of Mathematics, Statistics, and Computer, Ubon Ratchathani University, \\ Ubon Ratchathani 34190, Thailand \\ ${ }^{2}$ Department of Mathematics, Khon Kaen University, Khon Kaen 40002, Thailand
}

Correspondence should be addressed to Weerayuth Nilsrakoo,nilsrakoo@hotmail.com

Received 22 June 2010; Revised 14 September 2010; Accepted 12 October 2010

Academic Editor: W. A. Kirk

Copyright (C) 2010 W. Nilsrakoo and S. Saejung. This is an open access article distributed under the Creative Commons Attribution License, which permits unrestricted use, distribution, and reproduction in any medium, provided the original work is properly cited.

We modify the iterative method introduced by Kim and Xu (2006) for a countable family of Lipschitzian mappings by the hybrid method of Takahashi et al. (2008). Our results include recent ones concerning asymptotically nonexpansive mappings due to Plubtieng and Ungchittrakool (2007) and Zegeye and Shahzad $(2008,2010)$ as special cases.

\section{Introduction}

Let $C$ be a nonempty closed convex subset of a real Hilbert space $H$. A mapping $T: C \rightarrow C$ is said to be Lipschitzian if there exists a positive constant $L$ such that

$$
\|T x-T y\| \leq L\|x-y\| \quad \forall x, y \in C
$$

In this case, $T$ is also said to be $L$-Lipschitzian. Clearly, if $T$ is $L_{1}$-Lipschitzian and $L_{1}<L_{2}$, then $T$ is $L_{2}$-Lipschitzian. Throughout the paper, we assume that every Lipschitzian mapping is $L$-Lipschitzian with $L \geq 1$. If $L=1$, then $T$ is known as a nonexpansive mapping. We denote by $F(T)$ the set of fixed points of $T$. If $C$ is nonempty bounded closed convex and $T$ is a nonexpansive of $C$ into itself, then $F(T) \neq \varnothing$ (see [1]). There are many methods for approximating fixed points of a nonexpansive mapping. In 1953, Mann [2] introduced the iteration as follows: a sequence $\left\{x_{n}\right\}$ defined by

$$
x_{n+1}=\alpha_{n} x_{n}+\left(1-\alpha_{n}\right) T x_{n},
$$


where the initial guess element $x_{1} \in C$ is arbitrary and $\left\{\alpha_{n}\right\}$ is a real sequence in $[0,1]$. Mann iteration has been extensively investigated for nonexpansive mappings. One of the fundamental convergence results is proved by Reich [3]. In an infinite-dimensional Hilbert space, Mann iteration can conclude only weak convergence [4]. Attempts to modify the Mann iteration method (1.2) so that strong convergence is guaranteed have recently been made. Nakajo and Takahashi [5] proposed the following modification of Mann iteration method (1.2):

$$
\begin{gathered}
x_{1}=x \in C \text { is arbitrary, } \\
y_{n}=\alpha_{n} x_{n}+\left(1-\alpha_{n}\right) T x_{n}, \\
C_{n}=\left\{z \in C:\left\|y_{n}-z\right\| \leq\left\|x_{n}-z\right\|\right\}, \\
Q_{n}=\left\{z \in C:\left\langle x_{n}-z, x-x_{n}\right\rangle \geq 0\right\}, \\
x_{n+1}=P_{C_{n} \cap Q_{n}} x, \quad n=1,2,3, \ldots,
\end{gathered}
$$

where $P_{K}$ denotes the metric projection from $H$ onto a closed convex subset $K$ of $H$. They prove that if the sequence $\left\{\alpha_{n}\right\}$ bounded above from one, then $\left\{x_{n}\right\}$ defined by (1.3) converges strongly to $P_{F(T)} x$. Takahashi et al. [6] modified (1.3) so-called the shrinking projection method for a countable family of nonexpansive mappings $\left\{T_{n}\right\}_{n=1}^{\infty}$ as follows:

$$
\begin{gathered}
x_{1}=x \in H, \\
C_{1}=C, \\
y_{n}=\alpha_{n} x_{n}+\left(1-\alpha_{n}\right) T_{n} x_{n}, \\
C_{n+1}=\left\{z \in C_{n}:\left\|y_{n}-z\right\| \leq\left\|x_{n}-z\right\|\right\}, \\
x_{n+1}=P_{C_{n+1}} x, \quad n=1,2,3, \ldots,
\end{gathered}
$$

and prove that if the sequence $\left\{\alpha_{n}\right\}$ bounded above from one, then $\left\{x_{n}\right\}$ defined by (1.4) converges strongly to $P_{\cap_{n=1}^{\infty} F\left(T_{n}\right)} x$.

Recently, the present authors [7] extended (1.3) to obtain a strong convergence theorem for common fixed points of a countable family of $L_{n}$-Lipschitzian mappings $\left\{T_{n}\right\}_{n=1}^{\infty}$ by

$$
\begin{gathered}
x_{1}=x \in C \text { is arbitrary, } \\
y_{n}=\alpha_{n} x_{n}+\left(1-\alpha_{n}\right) T_{n} x_{n}, \\
C_{n}=\left\{z \in C:\left\|y_{n}-z\right\|^{2} \leq\left\|x_{n}-z\right\|^{2}+\theta_{n}\right\}, \\
Q_{n}=\left\{z \in C:\left\langle x_{n}-z, x-x_{n}\right\rangle \geq 0\right\}, \\
x_{n+1}=P_{C_{n} \cap Q_{n}} x, \quad n=1,2,3, \ldots,
\end{gathered}
$$


where $\theta_{n}=\left(1-\alpha_{n}\right)\left(L_{n}^{2}-1\right)(\operatorname{diam} C)^{2} \rightarrow 0$ as $n \rightarrow \infty$ and prove that $\left\{x_{n}\right\}$ defined by (1.5) converges strongly to $P_{\cap_{n=1}^{\infty} F\left(T_{n}\right)} x$.

In this paper, we establish strong convergence theorems for finding common fixed points of a countable family of Lipschitzian mappings in a real Hilbert space. Moreover, we also apply our results for asymptotically nonexpansive mappings.

\section{Preliminaries}

Let $H$ be a real Hilbert space with inner product $\langle\cdot, \cdot\rangle$ and norm $\|\cdot\|$. Then,

$$
\begin{gathered}
\|x-y\|^{2}=\|x\|^{2}-\|y\|^{2}-2\langle x-y, y\rangle, \\
\|\lambda x+(1-\lambda) y\|^{2}=\lambda\|x\|^{2}+(1-\lambda)\|y\|^{2}-\lambda(1-\lambda)\|x-y\|^{2},
\end{gathered}
$$

for all $x, y \in H$ and $\lambda \in[0,1]$. For any $n$ points $x_{1}, x_{2}, \ldots, x_{n}$ in $H$, the following generalized identity holds:

$$
\left\|\sum_{i=1}^{n} \lambda_{i} x_{i}\right\|^{2}=\sum_{i=1}^{n} \lambda_{i}\left\|x_{i}\right\|^{2}-\sum_{i<j} \lambda_{i} \lambda_{j}\left\|x_{i}-x_{j}\right\|^{2},
$$

where $\lambda_{i} \in[0,1]$ and $\sum_{i=1}^{n} \lambda_{i}=1$.

We write $x_{n} \rightarrow x\left(x_{n} \rightarrow x\right.$, resp.) if $\left\{x_{n}\right\}$ converges strongly (weakly, resp.) to $x$. It is also known that $H$ satisfies:

(1) the Opial's condition [8] that is, for any sequence $\left\{x_{n}\right\}$ with $x_{n} \rightarrow x$,

$$
\liminf _{n \rightarrow \infty}\left\|x_{n}-x\right\|<\liminf _{n \rightarrow \infty}\left\|x_{n}-y\right\|
$$

holds for every $y \in H$ with $y \neq x$

(2) the Kadec-Klee property $[9,10]$; that is, for any sequence $\left\{x_{n}\right\}$ with $x_{n} \rightarrow x$ and $\left\|x_{n}\right\| \rightarrow\|x\|$ together imply $x_{n} \rightarrow x$.

Let $C$ be a nonempty closed convex subset of $H$. Then, for any $x \in H$, there exists a unique nearest point in $C$, denoted by $P_{C} x$, such that

$$
\left\|x-P_{C} x\right\| \leq\|x-y\| \quad \forall y \in C .
$$

Such a mapping $P_{C}$ is called the metric projection of $H$ onto $C$. We know that $P_{C}$ is nonexpansive. Furthermore, for $x \in H$ and $z \in C$,

$$
z=P_{C} x \quad \text { iff }\langle x-z, z-y\rangle \geq 0, \forall y \in C .
$$

To deal with a family of mappings, the following conditions are introduced: let $C$ be a subset of a Banach space, let $\left\{T_{n}\right\}$ and $\tau$ be families of mappings of $C$ with $\bigcap_{n=1}^{\infty} F\left(T_{n}\right)=F(\tau) \neq \varnothing$, where $F(\tau)$ is the set of all common fixed points of all mappings in $\tau$. $\left\{T_{n}\right\}$ is said to satisfy 
(a) the AKTT-condition [11] if for each bounded subset $B$ of $C$,

$$
\sum_{n=1}^{\infty} \sup \left\{\left\|T_{n+1} z-T_{n} z\right\|: z \in B\right\}<\infty,
$$

(b) the NST-condition (I) with $\tau$ [12] if for each bounded sequence $\left\{z_{n}\right\}$ in $C$,

$$
\lim _{n \rightarrow \infty}\left\|z_{n}-T_{n} z_{n}\right\|=0 \text { implies } \lim _{n \rightarrow \infty}\left\|z_{n}-T z_{n}\right\|=0 \quad \forall T \in \tau,
$$

(c) the NST-condition (II) [12] if for each bounded sequence $\left\{z_{n}\right\}$ in $C$,

$$
\lim _{n \rightarrow \infty}\left\|z_{n+1}-T_{n} z_{n}\right\|=0 \text { implies } \lim _{n \rightarrow \infty}\left\|z_{n}-T_{m} z_{n}\right\|=0 \quad \forall m \in \mathbb{N},
$$

(d) NST*-condition with $\tau$ [13] if for each bounded sequence $\left\{z_{n}\right\}$ in $C$,

$$
\lim _{n \rightarrow \infty}\left\|z_{n}-T_{n} z_{n}\right\|=0, \quad \lim _{n \rightarrow \infty}\left\|z_{n}-z_{n+1}\right\|=0
$$

imply $\lim _{n \rightarrow \infty}\left\|z_{n}-T z_{n}\right\|=0$ for all $T \in \tau$.

In particular, if $\tau=\{T\}$, then we simply say that $\left\{T_{n}\right\}$ satisfies the NST-condition (I) with $T$ (NST ${ }^{*}$-condition with $T$, resp.) rather than NST-condition (I) with $\{T\}$ (NST*-condition with $\{T\}$, resp.).

Remark 2.1. It follows directly from the definitions above that

(i) if $\left\{T_{n}\right\}$ satisfies the NST-condition (I) with $\tau$, then $\left\{T_{n}\right\}$ satisfies the NST*-condition with $\tau$

(ii) if $\left\{T_{n}\right\}$ satisfies the NST-condition (II), then $\left\{T_{n}\right\}$ satisfies the NST*-condition with $\left\{T_{n}\right\}$.

Lemma 2.2 (see [11, Lemma 3.2]). Let $C$ be a nonempty closed subset of a Banach space, and let $\left\{T_{n}\right\}$ be a family of mappings of $C$ into itself which satisfies the AKTT-condition, then the mapping $T: C \rightarrow C$ defined by

$$
T x=\lim _{n \rightarrow \infty} T_{n} x \quad \forall x \in C
$$

satisfies

$$
\lim _{n \rightarrow \infty} \sup \left\{\left\|T z-T_{n} z\right\|: z \in B\right\}=0,
$$

for each bounded subset $B$ of $C$.

From now on, we will write $\left(\left\{T_{n}\right\}, T\right)$ satisfies AKTT-condition if $\left\{T_{n}\right\}$ satisfies AKTTcondition and $T$ is defined by (2.11). 
Lemma 2.3 (see [13, Lemma 2.6]). Let $C$ be a nonempty closed subset of a Banach space. Suppose that $\left(\left\{T_{n}\right\}, T\right)$ satisfies AKTT-condition and $F(T)=\bigcap_{n=1}^{\infty} F\left(T_{n}\right) \neq \varnothing$. Then, $\left\{T_{n}\right\}$ satisfies the NSTcondition (I) with T. Consequently, $\left\{T_{n}\right\}$ satisfies the NST*-condition with $T$.

Remark 2.4. There are families of mappings $\left\{T_{n}\right\}$ and $\tau$ such that

(1) $\left\{T_{n}\right\}$ satisfies the NST*-condition with $\tau$, and

(2) $\left\{T_{n}\right\}$ fails the NST-condition (I) with $\tau$ and the NST-condition (II).

The following example shows that the NST$^{*}$-condition with $\tau$ is strictly weaker than NST-condition (I) with $\tau$ and the NST-condition (II).

Example 2.5 (see [13, Example 2.9]). Let $H:=\mathbb{R}^{2}$ and $C:=[0,1] \times[0,1]$. Define $T_{1}, T_{2}: C \rightarrow C$ as follows:

$$
T_{1}(x, y)=(x, 1-y), \quad T_{2}(x, y)=(1-x, y),
$$

for all $(x, y) \in C$. Hence, $T_{1}$ and $T_{2}$ are nonexpansive mappings with

$$
F\left(T_{1}\right) \cap F\left(T_{2}\right)=\left([0,1] \times\left\{\frac{1}{2}\right\}\right) \cap\left(\left\{\frac{1}{2}\right\} \times[0,1]\right)=\left\{\left(\frac{1}{2}, \frac{1}{2}\right)\right\} \neq \varnothing
$$

Let $T_{n}=T_{n-1(\bmod 2)+1}$. Then, $\left\{T_{n}\right\}$ satisfies NST*-condition but it fails NST-condition (I) with $\tau$ and the NST-condition (II).

Lemma 2.6. Let $C$ be a nonempty closed convex subset of a real Hilbert space $H$. Let $\left\{T_{n}\right\}$ and $\left\{S_{n}\right\}$ be two families of $t_{n}$-Lipschitzian and $s_{n}$-Lipschitzian mappings of $C$ into itself, respectively. Let $\left\{U_{n}\right\}$ be a family of mappings of $C$ into itself defined by

$$
U_{n}=T_{n}\left(\beta_{n} I+\left(1-\beta_{n}\right) S_{n}\right) \quad \forall n \in \mathbb{N},
$$

where $\left\{\beta_{n}\right\}$ is a sequence in $[a, b]$ for some $a, b \in(0,1)$ and $I$ is an identity mapping. Assume that $\left\{t_{n}\right\}$ and $\left\{s_{n}\right\}$ are two sequences such that $t_{n} \rightarrow 1$ and $s_{n} \rightarrow 1$. Then, the following statements hold.

(i) $\left\{U_{n}\right\}$ is a family of $L_{n}$-Lipschitzian mappings of $C$ into itself, where $L_{n}=\left(\beta_{n} t_{n}^{2}+(1-\right.$ $\left.\left.\beta_{n}\right) t_{n}^{2} s_{n}^{2}\right)^{1 / 2}$ and $L_{n} \rightarrow 1$.

(ii) Suppose that $\tau_{1}$ and $\tau_{2}$ are families of mappings of $C$ into itself such that $F\left(\tau_{1}\right)=$ $\bigcap_{n=1}^{\infty} F\left(T_{n}\right), F\left(\tau_{2}\right)=\bigcap_{n=1}^{\infty} F\left(S_{n}\right)$ and $F\left(\tau_{1}\right) \cap F\left(\tau_{2}\right) \neq \varnothing$. If $\left\{T_{n}\right\}$ and $\left\{S_{n}\right\}$ satisfy the NST $T^{*}$-condition with $\tau_{1}$ and $\tau_{2}$, respectively, then $\left\{U_{n}\right\}$ satisfies the NST*-condition with $\tau_{1} \cup \tau_{2}$ and

$$
\bigcap_{n=1}^{\infty} F\left(U_{n}\right)=F\left(\tau_{1}\right) \cap F\left(\tau_{2}\right) .
$$


Proof. (i) We first observe that

$$
\begin{aligned}
\left\|U_{n} x-U_{n} y\right\|^{2} & \leq t_{n}^{2}\left\|\beta_{n}(x-y)+\left(1-\beta_{n}\right)\left(S_{n} x-S_{n} y\right)\right\|^{2} \\
& \leq t_{n}^{2}\left(\beta_{n}\|x-y\|^{2}+\left(1-\beta_{n}\right)\left\|S_{n} x-S_{n} y\right\|^{2}\right) \\
& \leq \beta_{n} t_{n}^{2}\|x-y\|^{2}+\left(1-\beta_{n}\right) t_{n}^{2} s_{n}^{2}\|x-y\|^{2} \\
& =L_{n}^{2}\|x-y\|^{2}
\end{aligned}
$$

for all $x, y \in C$. That is, $U_{n}$ is $L_{n}$-Lipschitzian. Since $t_{n} \rightarrow 1$ and $s_{n} \rightarrow 1$, it follows that $L_{n} \rightarrow 1$.

(ii) Let $\left\{z_{n}\right\}$ be a bounded sequence in $C$ such that $\lim _{n \rightarrow \infty}\left\|z_{n}-U_{n} z_{n}\right\|=\lim _{n \rightarrow \infty} \| z_{n+1}-$ $z_{n} \|=0$. Let $p \in F\left(\tau_{1}\right) \cap F\left(\tau_{2}\right)$, and let $M=\sup \left\{\left\|z_{n}-U_{n} z_{n}\right\|,\left\|z_{n}-p\right\|: n \in \mathbb{N}\right\}$. Then

$$
\begin{aligned}
\left\|z_{n}-p\right\|^{2} \leq & \left(\left\|z_{n}-U_{n} z_{n}\right\|+\left\|U_{n} z_{n}-p\right\|\right)^{2} \\
= & \left\|z_{n}-U_{n} z_{n}\right\|^{2}+2\left\|z_{n}-U_{n} z_{n}\right\|\left\|U_{n} z_{n}-p\right\|+\left\|U_{n} z_{n}-p\right\|^{2} \\
\leq & 3 M\left\|z_{n}-U_{n} z_{n}\right\|+\left\|T_{n}\left(\beta_{n} z_{n}+\left(1-\beta_{n}\right) S_{n} z_{n}\right)-T_{n} p\right\|^{2} \\
\leq & 3 M\left\|z_{n}-U_{n} z_{n}\right\|+t_{n}^{2}\left\|\beta_{n}\left(z_{n}-p\right)+\left(1-\beta_{n}\right)\left(S_{n} z_{n}-p\right)\right\|^{2} \\
= & 3 M\left\|z_{n}-U_{n} z_{n}\right\|+\beta_{n} t_{n}^{2}\left\|z_{n}-p\right\|^{2}+\left(1-\beta_{n}\right) t_{n}^{2}\left\|S_{n} z_{n}-p\right\|^{2} \\
& -\beta_{n}\left(1-\beta_{n}\right) t_{n}^{2}\left\|z_{n}-S_{n} z_{n}\right\|^{2} \\
\leq & 3 M\left\|z_{n}-U_{n} z_{n}\right\|+\beta_{n} t_{n}^{2}\left\|z_{n}-p\right\|^{2}+\left(1-\beta_{n}\right) t_{n}^{2} s_{n}^{2}\left\|z_{n}-p\right\|^{2} \\
& -a(1-b)\left\|z_{n}-S_{n} z_{n}\right\|^{2} \\
= & 3 M\left\|z_{n}-U_{n} z_{n}\right\|+L_{n}^{2}\left\|z_{n}-p\right\|^{2}-a(1-b)\left\|z_{n}-S_{n} z_{n}\right\|^{2},
\end{aligned}
$$

for all $n \in \mathbb{N}$. In particular,

$$
a(1-b)\left\|z_{n}-S_{n} z_{n}\right\|^{2} \leq 3 M\left\|z_{n}-U_{n} z_{n}\right\|+\left(L_{n}^{2}-1\right)\left\|z_{n}-p\right\|^{2} .
$$

So, we get

$$
\lim _{n \rightarrow \infty}\left\|z_{n}-S_{n} z_{n}\right\|=0 .
$$

Since $\left\{S_{n}\right\}$ satisfies the NST*-condition with $\tau_{2}$, we have

$$
\lim _{n \rightarrow \infty}\left\|z_{n}-S z_{n}\right\|=0 \quad \forall S \in \tau_{2} .
$$


Since

$$
\begin{aligned}
\left\|z_{n}-T_{n} z_{n}\right\| & \leq\left\|z_{n}-U_{n} z_{n}\right\|+\left\|U_{n} z_{n}-T_{n} z_{n}\right\| \\
& \leq\left\|z_{n}-U_{n} z_{n}\right\|+\left(1-\beta_{n}\right) t_{n}\left\|z_{n}-S_{n} z_{n}\right\|,
\end{aligned}
$$

it follows that

$$
\lim _{n \rightarrow \infty}\left\|z_{n}-T_{n} z_{n}\right\|=0
$$

Since $\left\{T_{n}\right\}$ satisfies the NST*-condition with $\tau_{1}$, we have

$$
\lim _{n \rightarrow \infty}\left\|z_{n}-T z_{n}\right\|=0 \quad \forall T \in \tau_{1} .
$$

It is easy to see that $F\left(\mathcal{\tau}_{1}\right) \cap F\left(\tau_{2}\right) \subset \bigcap_{n=1}^{\infty} F\left(U_{n}\right)$. To see the reverse inclusion, let $z \in$ $\bigcap_{n=1}^{\infty} F\left(U_{n}\right)$ follow the first part of the proof above but now let $z_{n} \equiv z$. Then, $z \in F\left(\tau_{1}\right) \cap$ $F\left(\tau_{2}\right)=F\left(\tau_{1} \cup \tau_{2}\right)$. Hence, $\left\{U_{n}\right\}$ satisfies the NST*-condition with $\tau_{1} \cup \tau_{2}$.

Lemma 2.7. Let $C$ be a nonempty closed convex subset of a real Hilbert space $H$. Let $\left\{T_{n i}\right\}_{n=1}^{\infty}$ be families of $L_{n i}$-Lipschitzian mappings of $C$ into itself for $i=1,2, \ldots, r$, respectively. Let $\left\{T_{n}\right\}$ be a family of mappings of $C$ into itself defined by

$$
T_{n}=\sum_{i=1}^{r} \beta_{n i} T_{n i} \quad \forall n \in \mathbb{N}
$$

where $\left\{\beta_{n i}\right\}_{n=1}^{\infty}$ are sequences in $[a, b]$ for some $a, b \in(0,1)$ satisfying $\sum_{i=1}^{r} \beta_{n i}=1$ for all $n \in \mathbb{N}$. Assume that $\left\{L_{n i}\right\}_{n=1}^{\infty}$ are sequences such that $L_{n i} \rightarrow 1$ as $n \rightarrow \infty$ for all $i=1,2, \ldots, r$. Then, the following statements hold.

(i) $\left\{T_{n}\right\}$ is a family of $L_{n}$-Lipschitzian mappings of $C$ into itself, where $L_{n}=\left(\sum_{i=1}^{r} \beta_{n i} L_{n i}^{2}\right)^{1 / 2}$ and $L_{n} \rightarrow 1$.

(ii) Suppose that $\tau_{i}$ are families of mappings of $C$ into itself such that $F\left(\tau_{i}\right)=\bigcap_{n=1}^{\infty} F\left(T_{n i}\right)$ for $i=1,2, \ldots, r$ and $\bigcap_{i=1}^{r} F\left(\tau_{i}\right) \neq \varnothing$. If $\left\{T_{n i}\right\}$ satisfies the $N_{S T}{ }^{*}$-condition with $\tau_{i}$ for all $i=1,2, \ldots, r$, then $\left\{T_{n}\right\}$ satisfies the NST*-condition with $\bigcup_{i=1}^{r} \tau_{i}$ and

$$
\bigcap_{n=1}^{\infty} F\left(T_{n}\right)=\bigcap_{i=1}^{r} F\left(\tau_{i}\right)
$$


Proof. (i) From (2.3), we have

$$
\begin{aligned}
\left\|T_{n} x-T_{n} y\right\|^{2} & =\left\|\sum_{i=1}^{r} \beta_{n i}\left(T_{n i} x-T_{n i} y\right)\right\|^{2} \\
& \leq \sum_{i=1}^{r} \beta_{n i}\left\|T_{n i} x-T_{n i} y\right\|^{2} \\
& \leq\left(\sum_{i=1}^{r} \beta_{n i} L_{n i}^{2}\right)\|x-y\|^{2} \\
& =L_{n}^{2}\|x-y\|^{2},
\end{aligned}
$$

for all $x, y \in C$. That is, $T_{n}$ is $L_{n}$-Lipschitzian. Since $L_{n i} \rightarrow 1$ for $i=1,2, \ldots, r$ and $\sum_{i=1}^{r} \beta_{n i}=1$, it follows that $L_{n} \rightarrow 1$.

(ii) Let $\left\{z_{n}\right\}$ be a bounded sequence in $C$ such that $\lim _{n \rightarrow \infty}\left\|z_{n}-T_{n} z_{n}\right\|=\lim _{n \rightarrow \infty} \| z_{n+1}-$ $z_{n} \|=0$. Let $p \in \bigcap_{i=1}^{r} F\left(\tau_{i}\right)$, and let $M=\sup \left\{\left\|z_{n}-T_{n} z_{n}\right\|,\left\|z_{n}-p\right\|: n \in \mathbb{N}\right\} ;$ it follows from (2.3) that

$$
\begin{aligned}
\left\|z_{n}-p\right\|^{2} & \leq\left(\left\|z_{n}-T_{n} z_{n}\right\|+\left\|T_{n} z_{n}-p\right\|\right)^{2} \\
& =\left\|z_{n}-T_{n} z_{n}\right\|^{2}+2\left\|z_{n}-T_{n} z_{n}\right\|\left\|T_{n} z_{n}-p\right\|+\left\|T_{n} z_{n}-p\right\|^{2} \\
& \leq 3 M\left\|z_{n}-T_{n} z_{n}\right\|+\left\|\sum_{i=1}^{r} \beta_{n i}\left(T_{n i} z_{n}-p\right)\right\|^{2} \\
& =3 M\left\|z_{n}-T_{n} z_{n}\right\|+\sum_{i=1}^{r} \beta_{n i}\left\|T_{n i} z_{n}-p\right\|^{2}-\sum_{i<j} \beta_{n i} \beta_{n j}\left\|T_{n i} z_{n}-T_{n j} z_{n}\right\|^{2} \\
& \leq 3 M\left\|z_{n}-T_{n} z_{n}\right\|+\sum_{i=1}^{r} \beta_{n i} L_{n i}^{2}\left\|z_{n}-p\right\|^{2}-a^{2} \sum_{i<j}\left\|T_{n i} z_{n}-T_{n j} z_{n}\right\|^{2} \\
& =3 M\left\|z_{n}-T_{n} z_{n}\right\|+L_{n}^{2}\left\|z_{n}-p\right\|^{2}-a^{2} \sum_{i<j}\left\|T_{n i} z_{n}-T_{n j} z_{n}\right\|^{2} .
\end{aligned}
$$

So, by (i), we get

$$
\lim _{n \rightarrow \infty}\left\|T_{n i} z_{n}-T_{n j} z_{n}\right\|=0 \quad \forall i, j \in\{1,2, \ldots, r\}
$$


For each $k=1,2, \ldots, r$, we have

$$
\begin{aligned}
\left\|z_{n}-T_{n k} z_{n}\right\| & \leq\left\|z_{n}-T_{n} z_{n}\right\|+\left\|T_{n} z_{n}-T_{n k} z_{n}\right\| \\
& =\left\|z_{n}-T_{n} z_{n}\right\|+\left\|\sum_{i=1}^{r} \beta_{n i}\left(T_{n i} z_{n}-T_{n k} z_{n}\right)\right\| \\
& \leq\left\|z_{n}-T_{n} z_{n}\right\|+\sum_{i=1}^{r} \beta_{n i}\left\|T_{n i} z_{n}-T_{n k} z_{n}\right\| \longrightarrow 0 .
\end{aligned}
$$

Since each family $\left\{T_{n k}\right\}_{n=1}^{\infty}$ satisfies the NST*-condition with $\tau_{k}$,

$$
\lim _{n \rightarrow \infty}\left\|z_{n}-T z_{n}\right\|=0 \quad \forall T \in \bigcup_{i=1}^{r} \tau_{i}
$$

It is easy to see that $\bigcap_{i=1}^{r} F\left(\mathcal{\tau}_{i}\right) \subset \bigcap_{n=1}^{\infty} F\left(T_{n}\right)$. To see the reverse inclusion, let $z \in \bigcap_{n=1}^{\infty} F\left(T_{n}\right)$. Follow the first part of the proof above but now let $z_{n} \equiv z$. Then, $z \in \bigcap_{i=1}^{r} F\left(\tau_{i}\right)=F\left(\cup_{i=1}^{r} \tau_{i}\right)$. Hence, $\left\{T_{n}\right\}$ satisfies the NST*-condition with $\bigcup_{i=1}^{r} \tau_{i}$.

Lemma 2.8. Let $C$ be a nonempty closed convex subset of a real Hilbert space $H$, and let $\left\{T_{n}\right\}$ be a family of $L_{n}$-Lipschitzian mappings of $C$ into itself with $L_{n} \rightarrow 1$ and $\bigcap_{n=1}^{\infty} F\left(T_{n}\right) \neq \varnothing$. If $\left\{T_{n}\right\}$ satisfies the NST*-condition with $\tau$, where $\tau$ is a family of mappings of $C$ into itself such that $F(\tau)=$ $\bigcap_{n=1}^{\infty} F\left(T_{n}\right)$, then $F(\tau)$ is closed and convex.

Proof. It follows from the continuity of $T_{n}$ that $F\left(T_{n}\right)$ is closed and so is $F(\tau)=\bigcap_{n=1}^{\infty} F\left(T_{n}\right)$. Now, we prove that $F(\tau)$ is convex. To this end, let $x, y \in F(\tau)$. Put $z=t x+(1-t) y$, where $t \in(0,1)$. From $(2.2)$, we have

$$
\begin{aligned}
\left\|z-T_{n} z\right\|^{2} & =t\left\|x-T_{n} z\right\|^{2}+(1-t)\left\|y-T_{n} z\right\|^{2}-t(1-t)\|x-y\|^{2} \\
& \leq t L_{n}^{2}\|x-z\|^{2}+(1-t) L_{n}^{2}\|y-z\|^{2}-t(1-t)\|x-y\|^{2} \\
& =t(1-t)\left(L_{n}^{2}-1\right)\|x-y\|^{2} .
\end{aligned}
$$

So, we get

$$
\lim _{n \rightarrow \infty}\left\|z-T_{n} z\right\|=0
$$

Since $\left\{T_{n}\right\}$ satisfies the NST*-condition with $\tau$, we have $\|z-T z\|=0$ for all $T \in \tau$. Then, $z \in F(\tau)$ and so $F(\tau)$ is convex.

Remark 2.9. The conclusions of Lemmas 2.6, 2.7, and 2.8 remain true if we replace a Hilbert space with a uniformly convex Banach space. Recall a Banach space $X$ is uniformly convex if for any $\varepsilon>0$, there exists $\delta>0$ such that $\|x\|=\|y\|=1$ and $\|x-y\| \geq \varepsilon$ imply $\|(x+y) / 2\| \leq 1-\delta$. 


\section{Main Results}

In this section, using the method introduced by Takahashi et al. [6], we obtain a strong convergence theorem for a countable family of Lipschitzian mappings.

Recall that a mapping $T: C \rightarrow C$ is closed (demiclosed, resp.) at $y$ if whenever $\left\{x_{n}\right\}$ is a sequence in $C$ satisfying $x_{n} \rightarrow x\left(x_{n} \rightarrow x\right.$, resp.) and $T x_{n} \rightarrow y$, then $x \in C$ and $T x=y$.

Theorem 3.1. Let $C$ be a nonempty bounded closed convex subset of a real Hilbert space $H$. Let $\left\{T_{n}\right\}$ be a family of $L_{n}$-Lipschitzian mappings of $C$ into itself with a common fixed point. Assume that $\left\{\alpha_{n}\right\}$ is a sequence in $[0, b]$ for some $b \in(0,1)$. For $x_{1}=x \in H$ and $C_{1}=C$, one defines a sequence $\left\{x_{n}\right\}$ of $C$ as follows:

$$
\begin{gathered}
y_{n}=\alpha_{n} x_{n}+\left(1-\alpha_{n}\right) T_{n} x_{n}, \\
C_{n+1}=\left\{z \in C_{n}:\left\|y_{n}-z\right\|^{2} \leq\left\|x_{n}-z\right\|^{2}+\theta_{n}\right\}, \\
x_{n+1}=P_{C_{n+1}} x, \quad n=1,2,3, \ldots,
\end{gathered}
$$

where

$$
\theta_{n}=\left(1-\alpha_{n}\right)\left(L_{n}^{2}-1\right)(\operatorname{diam} C)^{2} \longrightarrow 0 \quad \text { as } n \longrightarrow \infty
$$

Suppose that $\tau$ is a family of mappings of $C$ into itself such that $F(\tau)=\bigcap_{n=1}^{\infty} F\left(T_{n}\right)$ and $I-T$ is closed at 0 for all $T \in \tau$. If $\left\{T_{n}\right\}$ satisfies the NST*-condition with $\tau$, then $\left\{x_{n}\right\}$ converges strongly to $P_{F(\tau)} x$.

Proof. By Lemma 2.8, we have $F(\tau)$ is closed and convex. We now prove that $C_{n}$ is closed and convex for each $n \in \mathbb{N}$ by induction. It is obvious that $C_{1}=C$ is closed and convex. Assume that $C_{k}$ is closed and convex for some $k \in \mathbb{N}$. For $z \in C_{k}$, we know that

$$
\left\|y_{k}-z\right\|^{2} \leq\left\|x_{k}-z\right\|^{2}+\theta_{k}
$$

is equivalent to

$$
2\left\langle x_{k}-y_{k}, z\right\rangle \leq\left\|x_{k}\right\|^{2}-\left\|y_{k}\right\|^{2}+\theta_{k}
$$

It follows that $C_{k+1}$ is closed and convex. Next, we show that

$$
F(\tau) \subset C_{n} \quad \forall n \in \mathbb{N}
$$


It is clear that $F(\tau) \subset C_{1}=C$. Suppose that $F(\tau) \subset C_{k}$ for some $k \in \mathbb{N}$. Then, for $p \in F(\tau)$,

$$
\begin{aligned}
\left\|y_{k}-p\right\|^{2} & =\left\|\alpha_{k} x_{k}+\left(1-\alpha_{n}\right) T_{k} x_{k}-p\right\|^{2} \\
& \leq \alpha_{k}\left\|x_{k}-p\right\|^{2}+\left(1-\alpha_{k}\right)\left\|T_{k} x_{k}-p\right\|^{2} \\
& \leq \alpha_{k}\left\|x_{k}-p\right\|^{2}+\left(1-\alpha_{k}\right) L_{k}^{2}\left\|x_{k}-p\right\|^{2} \\
& =\left\|x_{k}-p\right\|^{2}+\left(1-\alpha_{k}\right)\left(L_{k}^{2}-1\right)\left\|x_{k}-p\right\|^{2} \\
& \leq\left\|x_{k}-p\right\|^{2}+\theta_{k},
\end{aligned}
$$

we have $p \in C_{k+1}$. Therefore, we obtain (3.5). Now, the sequence $\left\{x_{n}\right\}$ is well defined. As $x_{n}=P_{C_{n}} x$,

$$
\left\|x_{n}-x\right\| \leq\|z-x\| \quad \forall z \in C_{n}, \forall n \in \mathbb{N} .
$$

In particular, since $F(\tau) \subset C_{n}$,

$$
\left\|x_{n}-x\right\| \leq\|p-x\| \quad \forall p \in F(\tau), \forall n \in \mathbb{N} .
$$

On the other hand, from $x_{n}=P_{C_{n}} x$ and $x_{n+1} \in C_{n+1} \subset C_{n}$, we have

$$
\left\|x_{n}-x\right\| \leq\left\|x_{n+1}-x\right\| \quad \forall n \in \mathbb{N} .
$$

Therefore, $\left\{\left\|x_{n}-x\right\|\right\}$ is nondecreasing and bounded. So,

$$
\lim _{n \rightarrow \infty}\left\|x_{n}-x\right\| \text { exists. }
$$

Noticing again that $x_{n}=P_{C_{n}} x$ and for any positive integer $k, x_{n+k} \in C_{n+k-1} \subset C_{n}$, we have

$$
\left\langle x_{n}-x_{n+k}, x-x_{n}\right\rangle \geq 0
$$

It follows from (2.1) that

$$
\begin{aligned}
\left\|x_{n+k}-x_{n}\right\|^{2} & =\left\|\left(x_{n+k}-x\right)-\left(x_{n}-x\right)\right\|^{2} \\
& =\left\|x_{n+k}-x\right\|^{2}-\left\|x_{n}-x\right\|^{2}-2\left\langle x_{n+k}-x_{n}, x_{n}-x\right\rangle \\
& \leq\left\|x_{n+k}-x\right\|^{2}-\left\|x_{n}-x\right\|^{2} .
\end{aligned}
$$

It then follows from the existence of $\lim _{n \rightarrow \infty}\left\|x_{n}-x\right\|^{2}$ that $\left\{x_{n}\right\}$ is a Cauchy sequence. Moreover,

$$
\lim _{n \rightarrow \infty}\left\|x_{n+1}-x_{n}\right\|=0 .
$$


We now assume that $x_{n} \rightarrow w$ for some $w \in C$. Now, since $x_{n+1} \in C_{n+1}$ and $C_{n+1} \subset C_{n}$, $\left\|y_{n}-x_{n+1}\right\|^{2} \leq\left\|x_{n}-x_{n+1}\right\|^{2}+\theta_{n}$ which implies that

$$
\left\|y_{n}-x_{n+1}\right\| \leq\left\|x_{n}-x_{n+1}\right\|+\sqrt{\theta_{n}} \longrightarrow 0
$$

From $\alpha_{n} \leq b<1$, we get

$$
\begin{aligned}
\left\|x_{n}-T_{n} x_{n}\right\| & =\frac{1}{1-\alpha_{n}}\left\|y_{n}-x_{n}\right\| \\
& \leq \frac{1}{1-b}\left(\left\|y_{n}-x_{n+1}\right\|+\left\|x_{n}-x_{n+1}\right\|\right) \longrightarrow 0 .
\end{aligned}
$$

Since $\left\{T_{n}\right\}$ satisfies the NST ${ }^{*}$-condition with $\tau$, we have

$$
\lim _{n \rightarrow \infty}\left\|x_{n}-T x_{n}\right\|=0 \quad \forall T \in \tau
$$

Since $I-T$ is closed at 0 for all $T \in \tau$, we have $(I-T) w=0$. This implies that $w \in F(\tau)$. Furthermore, by (3.8),

$$
\|w-x\|=\lim _{n \rightarrow \infty}\left\|x_{n}-x\right\| \leq\|p-x\| \quad \forall p \in F(\tau) .
$$

Hence, $w=P_{F(\tau)} x$. This completes the proof.

Lemma 3.2 (see [9, Theorem 10.4]). Let $C$ be a nonempty closed convex subset of a real Hilbert space, and let $T: C \rightarrow C$ be a nonexpansive mapping. Then, $I-T$ is demiclosed at 0 .

It is not difficult to see from the proof of Theorem 3.1 that the boundedness of $C$ can be discarded if $\left\{T_{n}\right\}$ is a family of nonexpansive mappings. So, we immediately obtain the following theorem.

Theorem 3.3. Let $C$ be a nonempty closed convex subset of a real Hilbert space $H$. Let $\left\{T_{n}\right\}$ and $\tau$ be two families of nonexpansive mappings of $C$ into itself such that $\bigcap_{n=1}^{\infty} F\left(T_{n}\right)=F(\tau) \neq \varnothing$ and suppose that $\left\{T_{n}\right\}$ satisfies the NST*-condition with $\tau$. Assume that $\left\{\alpha_{n}\right\}$ is a sequence in $[0, b]$ for some $b \in(0,1)$. Then, the sequence $\left\{x_{n}\right\}$ in $C$ defined by (1.4) converges strongly to $P_{F(\tau)} x$.

Remark 3.4. Theorem 3.3 includes [6, Theorem 3.3] as a special case since the NST-condition (I) with $\tau$ implies the NST*-condition with $\tau$.

Theorem 3.5. Let $C$ be a nonempty bounded closed convex subset of a real Hilbert space $H$. Let $\left\{T_{n}\right\}$ be a family of $L_{n}$-Lipschitzian mappings of $C$ into itself with a common fixed point. Suppose that $\tau$ is a family of mappings from $C$ into itself such that $F(\tau)=\bigcap_{n=1}^{\infty} F\left(T_{n}\right)$ and $I-T$ is demiclosed at 0 for all $T \in \tau$. Assume that $\left\{\alpha_{n}\right\}$ is a sequence in $[0, b]$ for some $b \in(0,1)$. If $\left\{T_{n}\right\}$ satisfies the NST ${ }^{*}$-condition with $\tau$, then the sequence $\left\{x_{n}\right\}$ in $C$ defined by (1.5) converges strongly to $P_{F(\tau)} x$.

Proof. The proof is analogous to the proof of [7, Theorem 10] and Theorem 3.1, so it is omitted. 


\section{Deduced Results}

Let $C$ be a subset of a real Hilbert space $H$. A mapping $T: C \rightarrow C$ is said to be an asymptotically nonexpansive if there exists a sequence $\left\{k_{n}\right\}$ of real numbers such that $k_{n} \in$ $[1, \infty), k_{n} \rightarrow 1$, and

$$
\left\|T^{n} x-T^{n} y\right\| \leq k_{n}\|x-y\| \quad \forall x, y \in C, n \in \mathbb{N} .
$$

The class of asymptotically nonexpansive mappings was introduced by Goebel and Kirk [14] as an important generalization of the class of nonexpansive mappings. They proved that if $C$ is nonempty bounded closed convex and $T$ is an asymptotically nonexpansive self-mapping of $C$, then $T$ has a fixed point.

In this section, we use the NST*-condition to obtain recent results proved by Kim and Xu [15], Plubtieng and Ungchittrakool [16], and Zegeye and Shahzad [17, 18]. We start with the following auxiliary result.

Lemma 4.1. Let $C$ be a nonempty closed convex subset of a Hilbert space $H$, and let $T$ be an asymptotically nonexpansive mappings of $C$ into itself with a sequence $\left\{k_{n}\right\}$ in $[1, \infty)$ satisfying $k_{n} \rightarrow 1$ and $F(T) \neq \varnothing$. Then, $\left\{T^{n}\right\}$ is a family of $k_{n}$-Lipschitzian mappings of $C$ into itself and satisfies the NST*-condition with $T$.

Proof. We note that $\left\{T^{n}\right\}$ is a family of $k_{n}$-Lipschitzian mappings of $C$ into itself. Let $\left\{z_{n}\right\}$ be a bounded sequence in $C$ such that

$$
\lim _{n \rightarrow \infty}\left\|z_{n}-T^{n} z_{n}\right\|=0, \quad \lim _{n \rightarrow \infty}\left\|z_{n+1}-z_{n}\right\|=0
$$

Since

$$
\begin{aligned}
\left\|z_{n+1}-T z_{n+1}\right\| & \leq\left\|z_{n+1}-T^{n+1} z_{n+1}\right\|+\left\|T^{n+1} z_{n+1}-T z_{n+1}\right\| \\
& \leq\left\|z_{n+1}-T^{n+1} z_{n+1}\right\|+k_{1}\left\|T^{n} z_{n+1}-z_{n+1}\right\| \\
& \leq\left\|z_{n+1}-T^{n+1} z_{n+1}\right\|+k_{1}\left(\left\|T^{n} z_{n+1}-T^{n} z_{n}\right\|+\left\|T^{n} z_{n}-z_{n}\right\|+\left\|z_{n+1}-z_{n}\right\|\right) \\
& \leq\left\|z_{n+1}-T^{n+1} z_{n+1}\right\|+k_{1}\left(k_{n}+1\right)\left\|z_{n+1}-z_{n}\right\|+k_{1}\left\|T^{n} z_{n}-z_{n}\right\|,
\end{aligned}
$$

it follows that

$$
\lim _{n \rightarrow \infty}\left\|z_{n}-T z_{n}\right\|=0
$$

It is easy to see that $F(T) \subset \bigcap_{n=1}^{\infty} F\left(T^{n}\right)$. To see the reverse inclusion, let $z \in \bigcap_{n=1}^{\infty} F\left(T^{n}\right)$ following from the first part of the proof above, but now let $z_{n} \equiv z$. Then, $z \in \bigcap_{n=1}^{\infty} F\left(T^{n}\right)$, and hence $\bigcap_{n=1}^{\infty} F\left(T^{n}\right) \subset F(T)$. This implies that $\left\{T^{n}\right\}$ satisfies the NST ${ }^{*}$-condition with $T$.

Lemma 4.2 (see [19]). Let $C$ be a nonempty bounded closed convex subset of a Hilbert space $H$, and let $T$ be an asymptotically nonexpansive mappings of $C$ into itself. Then, $I-T$ is demiclosed at 0. 
Using Theorem 3.1 and Lemmas 2.6 and 4.1, we have the following result.

Theorem 4.3. Let $C$ be a nonempty bounded closed convex subset of a real Hilbert space $H$, and let $S, T$ be two asymptotically nonexpansive mappings of $C$ into itself with sequences $\left\{s_{n}\right\}$ and $\left\{t_{n}\right\}$, respectively, and $F(S) \cap F(T) \neq \varnothing$. Assume that $\left\{\alpha_{n}\right\}$ is a sequence in $[0, b]$ and $\left\{\beta_{n}\right\}$ is a sequence in $[a, b]$ for some $a, b \in(0,1)$. For $x_{1}=x \in H$ and $C_{1}=C$, one defines a sequence $\left\{x_{n}\right\}$ of $C$ as follows:

$$
\begin{gathered}
z_{n}=\beta_{n} x_{n}+\left(1-\beta_{n}\right) S^{n} x_{n}, \\
y_{n}=\alpha_{n} x_{n}+\left(1-\alpha_{n}\right) T^{n} z_{n}, \\
C_{n+1}=\left\{z \in C_{n}:\left\|y_{n}-z\right\|^{2} \leq\left\|x_{n}-z\right\|^{2}+\theta_{n}\right\}, \\
x_{n+1}=P_{C_{n+1}} x, \quad n=1,2,3, \ldots,
\end{gathered}
$$

where

$$
\theta_{n}=\left(1-\alpha_{n}\right)\left(\left(t_{n}^{2}-1\right)+\left(1-\beta_{n}\right) t_{n}^{2}\left(s_{n}^{2}-1\right)\right)(\operatorname{diam} C)^{2} \longrightarrow 0 \quad \text { as } n \longrightarrow \infty
$$

Then, $\left\{x_{n}\right\}$ converges strongly to $P_{F(S) \cap F(T)} x$.

Using Theorem 3.5 and Lemmas 2.6 and 4.1, we have the following result.

Theorem 4.4 (see [16, Theorem 3.1]). Let $C$ be a nonempty bounded closed convex subset of a real Hilbert space $H$, and let $S, T$ be two asymptotically nonexpansive mappings of $C$ into itself with sequences $\left\{s_{n}\right\}$ and $\left\{t_{n}\right\}$, respectively, and $F(S) \cap F(T) \neq \varnothing$. Assume that $\left\{\alpha_{n}\right\}$ is a sequence in $[0, b]$ and $\left\{\beta_{n}\right\}$ is a sequence in $[a, b]$ for some $a, b \in(0,1)$. For $x_{1}=x \in C$, one defines a sequence $\left\{x_{n}\right\}$ of $C$ as follows:

$$
\begin{gathered}
z_{n}=\beta_{n} x_{n}+\left(1-\beta_{n}\right) S^{n} x_{n}, \\
y_{n}=\alpha_{n} x_{n}+\left(1-\alpha_{n}\right) T^{n} z_{n}, \\
C_{n}=\left\{z \in C:\left\|y_{n}-z\right\|^{2} \leq\left\|x_{n}-z\right\|^{2}+\theta_{n}\right\}, \\
Q_{n}=\left\{z \in C:\left\langle x_{n}-z, x-x_{n}\right\rangle \geq 0\right\}, \\
x_{n+1}=P_{C_{n} \cap Q_{n}} x, \quad n=1,2,3, \ldots,
\end{gathered}
$$

where

$$
\theta_{n}=\left(1-\alpha_{n}\right)\left(\left(t_{n}^{2}-1\right)+\left(1-\beta_{n}\right) t_{n}^{2}\left(s_{n}^{2}-1\right)\right)(\operatorname{diam} C)^{2} \longrightarrow 0 \quad \text { as } n \longrightarrow \infty
$$

Then, $\left\{x_{n}\right\}$ converges strongly to $P_{F(S) \cap F(T)} x$. 
Using Theorem 3.1 and Lemmas 2.7 and 4.1, we have the following result.

Theorem 4.5. Let $C$ be a nonempty bounded closed convex subset of a real Hilbert space $H$. Let $\left\{T_{i}\right\}_{i=1}^{r}$ be a finite family of asymptotically nonexpansive mappings of $C$ into itself with sequences $\left\{k_{n i}\right\}$ for $i=1,2, \ldots, r$, respectively, and suppose that $\bigcap_{i=1}^{r} F\left(T_{i}\right) \neq \varnothing$. Assume that $\left\{\alpha_{n i}\right\}_{n=1}^{\infty}$ are sequences in $[0,1)$ such that $\alpha_{n 0} \leq b<1, \alpha_{n i} \geq a>0$ for some $a, b \in(0,1)$ and $\sum_{i=0}^{r} \alpha_{n i}=1$ for all $n \in \mathbb{N}$. For $x_{1}=x \in H$ and $C_{1}=C$, one defines a sequence $\left\{x_{n}\right\}$ of $C$ as follows:

$$
\begin{gathered}
y_{n}=\alpha_{n 0} x_{n}+\alpha_{n 1} T_{1}^{n} x_{n}+\alpha_{n 2} T_{2}^{n} x_{n}+\cdots+\alpha_{n r} T_{r}^{n} x_{n}, \\
C_{n+1}=\left\{z \in C_{n}:\left\|y_{n}-z\right\|^{2} \leq\left\|x_{n}-z\right\|^{2}+\theta_{n}\right\}, \\
x_{n+1}=P_{C_{n+1}} x, \quad n=1,2,3, \ldots,
\end{gathered}
$$

where

$$
\theta_{n}=\left(\alpha_{n 1}\left(k_{n 1}^{2}-1\right)+\alpha_{n 2}\left(k_{n 2}^{2}-1\right)+\cdots+\alpha_{n r}\left(k_{n r}^{2}-1\right)\right)(\operatorname{diam} C)^{2} \longrightarrow 0 \quad \text { as } n \longrightarrow \infty \text {. }
$$

Then, $\left\{x_{n}\right\}$ converges strongly to $P_{\bigcap_{i=1}^{r} F\left(T_{i}\right)} x$.

Using Theorem 3.5 and Lemmas 2.7 and 4.1, we have the following two results which were proved by Zegeye and Shahzad [17, 18].

Theorem 4.6. Let $C$ be a nonempty bounded closed convex subset of a real Hilbert space $H$. Let $\left\{T_{i}\right\}_{i=1}^{r}$ be a finite family of asymptotically nonexpansive mappings of $C$ with sequences $\left\{k_{n i}\right\}$ for $i=1,2, \ldots, r$, respectively, and suppose that $\bigcap_{i=1}^{r} F\left(T_{i}\right) \neq \varnothing$. Assume that $\left\{\alpha_{n i}\right\}_{n=1}^{\infty}$ are sequences in $[0,1)$ such that $\alpha_{n 0} \leq b<1, \alpha_{n i} \geq a>0$ for some $a, b \in(0,1)$ and $\sum_{i=0}^{r} \alpha_{n i}=1$ for all $n \in \mathbb{N}$. For $x_{1}=x \in C$, one defines a sequence $\left\{x_{n}\right\}$ of $C$ as follows:

$$
\begin{aligned}
y_{n} & =\alpha_{n 0} x_{n}+\alpha_{n 1} T_{1}^{n} x_{n}+\alpha_{n 2} T_{2}^{n} x_{n}+\cdots+\alpha_{n r} T_{r}^{n} x_{n}, \\
C_{n} & =\left\{z \in C:\left\|y_{n}-z\right\|^{2} \leq\left\|x_{n}-z\right\|^{2}+\theta_{n}\right\}, \\
Q_{n} & =\left\{z \in C:\left\langle x_{n}-z, x-x_{n}\right\rangle \geq 0\right\}, \\
x_{n+1} & =P_{C_{n} \cap Q_{n}} x, \quad n=1,2,3, \ldots,
\end{aligned}
$$

where

$$
\theta_{n}=\left(\alpha_{n 1}\left(k_{n 1}^{2}-1\right)+\alpha_{n 2}\left(k_{n 2}^{2}-1\right)+\cdots+\alpha_{n r}\left(k_{n r}^{2}-1\right)\right)(\operatorname{diam} C)^{2} \longrightarrow 0 \quad \text { as } n \longrightarrow \infty .
$$

Then, $\left\{x_{n}\right\}$ converges strongly to $P_{\bigcap_{i=1}^{r} F\left(T_{i}\right)} x$. 
Theorem 4.7. Let $C$ be a nonempty bounded closed convex subset of a real Hilbert space $H$. Let $\mathfrak{T}_{i}=\left\{T_{i}(t): t \in \mathbb{R}^{+}, i=1,2, \ldots, r\right\}$ be a finite family of asymptotically nonexpansive semigroups such that $F=\bigcap_{i=1}^{r} F\left(\mathfrak{T}_{i}\right) \neq \varnothing$. Assume that $\left\{\alpha_{n i}\right\}_{n=1}^{\infty}$ are sequences in $[0,1)$ such that

$$
\alpha_{n 0} \leq b<1, \quad \alpha_{n i} \geq a>0,
$$

for some $a, b \in(0,1)$ and $\sum_{i=0}^{r} \alpha_{n i}=1$ for all $n \in \mathbb{N}$. Let $\left\{t_{n i}, i=1,2, \ldots, r\right\}$ be finite positive and divergent real sequences. For $x_{1}=x \in C$, one defines a sequence $\left\{x_{n}\right\}$ of $C$ as follows:

$$
\begin{aligned}
y_{n}= & \alpha_{n 0} x_{n}+\alpha_{n 1} \frac{1}{t_{n 1}} \int_{0}^{t_{n 1}} T_{1}(u) x_{n} d u+\alpha_{n 2} \frac{1}{t_{n 2}} \int_{0}^{t_{n 2}} T_{2}(u) x_{n} d u \\
& +\cdots+\alpha_{n r} \frac{1}{t_{n r}} \int_{0}^{t_{n r}} T_{r}(u) x_{n} d u, \\
C_{n}= & \left\{z \in C:\left\|y_{n}-z\right\|^{2} \leq\left\|x_{n}-z\right\|^{2}+\theta_{n}\right\}, \\
Q_{n}= & \left\{z \in C:\left\langle x_{n}-z, x-x_{n}\right\rangle \geq 0\right\}, \\
x_{n+1}= & P_{C_{n} \cap Q_{n}} x, \quad n=1,2,3, \ldots,
\end{aligned}
$$

where

$$
\bar{\theta}_{n}=\left(\alpha_{n 1}\left(L_{u 1}^{2}-1\right)+\alpha_{n 2}\left(L_{u 2}^{2}-1\right)+\cdots+\alpha_{n r}\left(L_{u r}^{2}-1\right)\right)(\operatorname{diam} C)^{2} \longrightarrow 0 \quad \text { as } n \longrightarrow \infty,
$$

with $L_{u i}=\left(1 / t_{n i}\right) \int_{0}^{t_{n i}} L_{i}^{T_{i}} d u$. Then $\left\{x_{n}\right\}$ converges strongly to $P_{F} x$.

\section{Acknowledgments}

The authors would like to thank the referee for the insightful comments and suggestions. The second author was supported by the Commission on Higher Education, the Thailand Research Fund, and Khon Kaen University under Grant no. RMU5380039.

\section{References}

[1] F. E. Browder, "Nonexpansive nonlinear operators in a Banach space," Proceedings of the National Academy of Sciences of the United States of America, vol. 54, pp. 1041-1044, 1965.

[2] W. R. Mann, "Mean value methods in iteration," Proceedings of the American Mathematical Society, vol. 4, pp. 506-510, 1953.

[3] S. Reich, "Weak convergence theorems for nonexpansive mappings in Banach spaces," Journal of Mathematical Analysis and Applications, vol. 67, no. 2, pp. 274-276, 1979.

[4] A. Genel and J. Lindenstrauss, "An example concerning fixed points," Israel Journal of Mathematics, vol. 22, no. 1, pp. 81-86, 1975.

[5] K. Nakajo and W. Takahashi, "Strong convergence theorems for nonexpansive mappings and nonexpansive semigroups," Journal of Mathematical Analysis and Applications, vol. 279, no. 2, pp. 372379, 2003.

[6] W. Takahashi, Y. Takeuchi, and R. Kubota, "Strong convergence theorems by hybrid methods for families of nonexpansive mappings in Hilbert spaces," Journal of Mathematical Analysis and Applications, vol. 341, no. 1, pp. 276-286, 2008. 
[7] W. Nilsrakoo and S. Saejung, "Weak and strong convergence theorems for countable Lipschitzian mappings and its applications," Nonlinear Analysis. Theory, Methods E Applications, vol. 69, no. 8, pp. 2695-2708, 2008.

[8] Z. Opial, "Weak convergence of the sequence of successive approximations for nonexpansive mappings," Bulletin of the American Mathematical Society, vol. 73, pp. 591-597, 1967.

[9] K. Goebel and W. A. Kirk, Topics in Metric Fixed Point Theory, vol. 28 of Cambridge Studies in Advanced Mathematics, Cambridge University Press, Cambridge, UK, 1990.

[10] W. Takahashi, Nonlinear Functional Analysis, Yokohama Publishers, Yokohama, Japan, 2000, Fixed point theory and Its application.

[11] K. Aoyama, Y. Kimura, W. Takahashi, and M. Toyoda, "Approximation of common fixed points of a countable family of nonexpansive mappings in a Banach space," Nonlinear Analysis. Theory, Methods $\mathcal{E}$ Applications, vol. 67, no. 8, pp. 2350-2360, 2007.

[12] K. Nakajo, K. Shimoji, and W. Takahashi, "Strong convergence to common fixed points of families of nonexpansive mappings in Banach spaces," Journal of Nonlinear and Convex Analysis, vol. 8, no. 1, pp. 11-34, 2007.

[13] K. Nakprasit, W. Nilsrakoo, and S. Saejung, "Weak and strong convergence theorems of an implicit iteration process for a countable family of nonexpansive mappings," Fixed Point Theory and Applications, vol. 2008, Article ID 732193, 18 pages, 2008.

[14] K. Goebel and W. A. Kirk, "A fixed point theorem for asymptotically nonexpansive mappings," Proceedings of the American Mathematical Society, vol. 35, pp. 171-174, 1972.

[15] T.-H. Kim and H.-K. Xu, "Strong convergence of modified Mann iterations for asymptotically nonexpansive mappings and semigroups," Nonlinear Analysis. Theory, Methods \& Applications, vol. 64, no. 5, pp. 1140-1152, 2006.

[16] S. Plubtieng and K. Ungchittrakool, "Strong convergence of modified Ishikawa iteration for two asymptotically nonexpansive mappings and semigroups," Nonlinear Analysis. Theory, Methods $\mathcal{E}$ Applications, vol. 67, no. 7, pp. 2306-2315, 2007.

[17] H. Zegeye and N. Shahzad, "Strong convergence theorems for a finite family of asymptotically nonexpansive mappings and semigroups," Nonlinear Analysis. Theory, Methods \& Applications, vol. 69, no. 12, pp. 4496-4503, 2008.

[18] H. Zegeye and N. Shahzad, "Corrigendum to: Strong convergence theorems for a finite family of asymptotically nonexpansive mappings and semigroups," Nonlinear Analysis. Theory, Methods $\mathcal{E}$ Applications, vol. 69, no. 12, pp. 4496-4503, 2008, Nonlinear Analysis, Theory, Methods and Applications, vol. 73, pp. 1905-1907, 2010.

[19] P.-K. Lin, K.-K. Tan, and H. K. Xu, "Demiclosedness principle and asymptotic behavior for asymptotically nonexpansive mappings," Nonlinear Analysis. Theory, Methods E Applications, vol. 24, no. 6, pp. 929-946, 1995. 


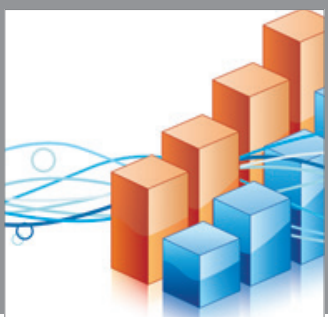

Advances in

Operations Research

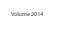

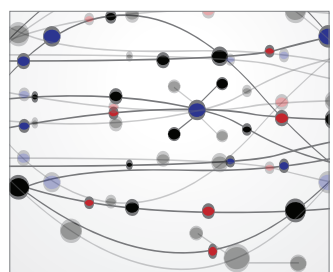

\section{The Scientific} World Journal
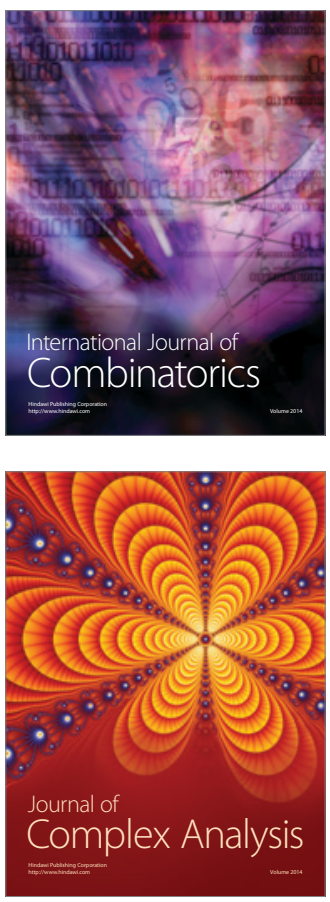

International Journal of

Mathematics and

Mathematical

Sciences
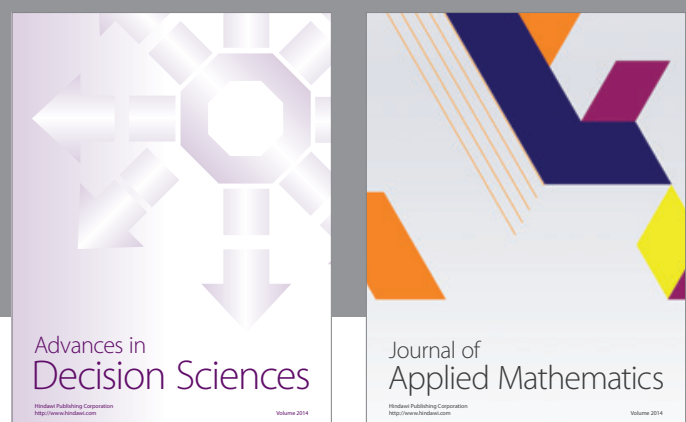

Journal of

Applied Mathematics
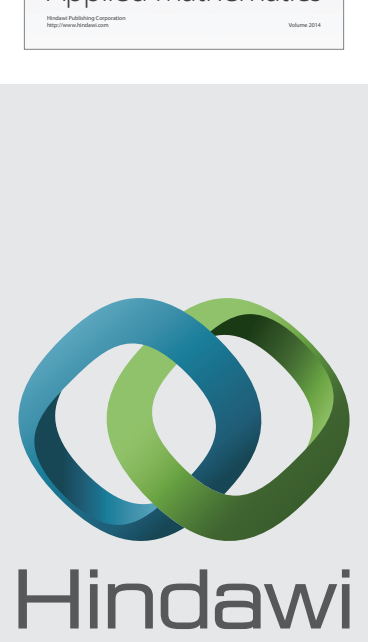

Submit your manuscripts at http://www.hindawi.com
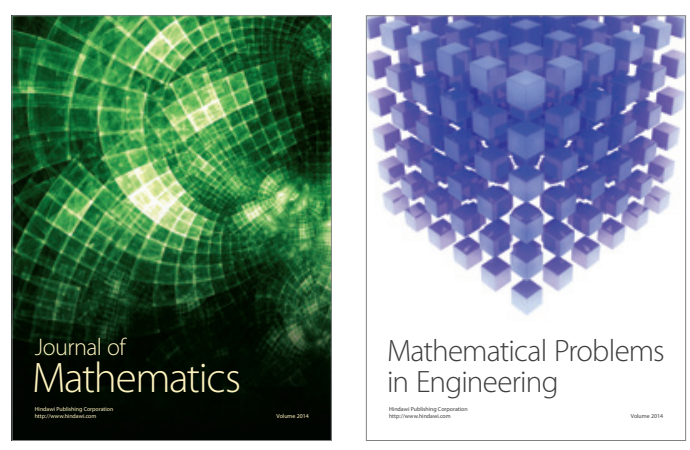

Mathematical Problems in Engineering
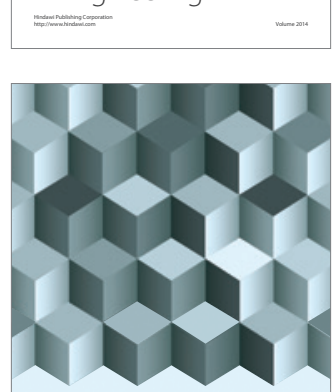

Journal of

Function Spaces
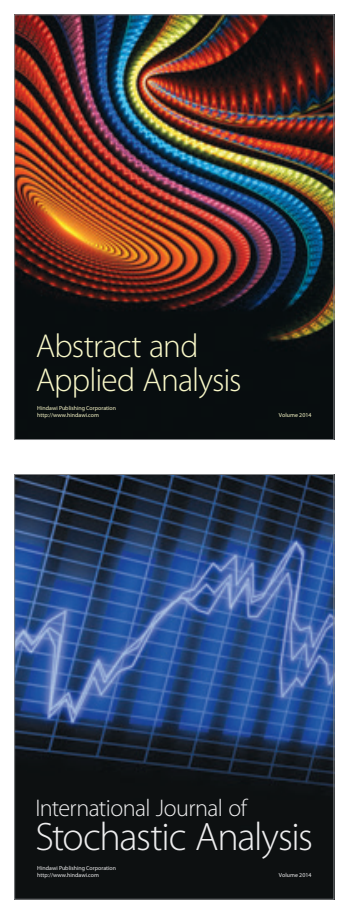

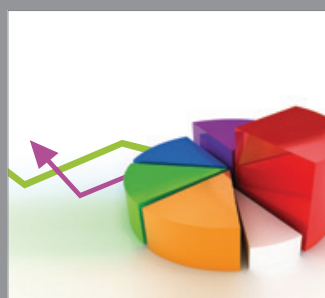

ournal of

Probability and Statistics

Promensencen
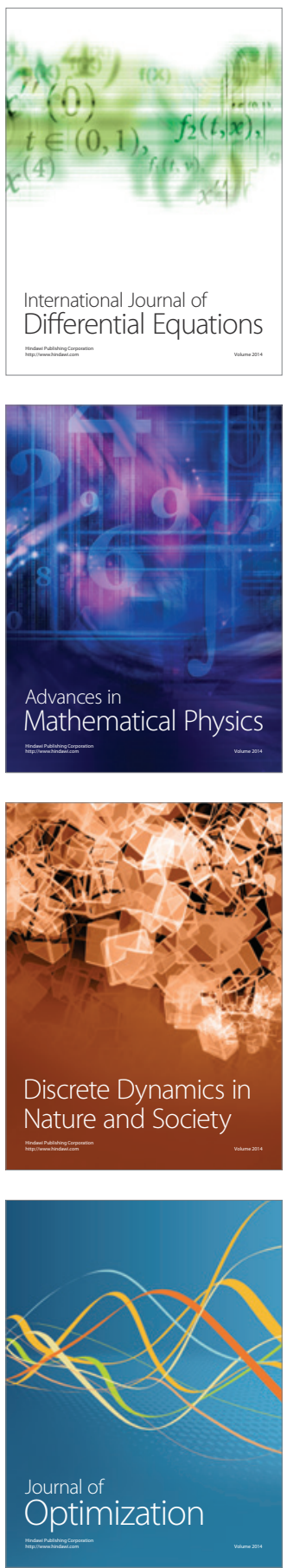